\title{
Ortognatik cerrahinin maksiller sinüs ventilasyon hacmi üzerine etkisinin KIBT ile değerlendirilmesi ${ }^{*}$
}

\author{
Hazal Duyan(0000-0002-2765-0631) ${ }^{\alpha}$, Burcu Evlice(0000-0003-3384-0092) ${ }^{\alpha}$
}

Selcuk Dent J, 2020; 7: 180-184 (Doi: 10.15311/selcukdentj.509721)

Başvuru Tarihi: 07 Ocak 2019 Yayına Kabul Tarihi: 03 Nisan 2019

öz

Ortognatik cerrahinin maksiller sinüs ventilasyon hacmi üzerine etkisinin KIBT ile değerlendirilmesi

Amaç: Bu çalışmanın amacı Le Fort I osteotomisi sonrası maksiller sinüslerdeki anatomik ve morfolojik değişikliklerin konik ışınlı bilgisayarlı tomografi (KIBT) ile gösterilmesiydi.

Gereç ve Yöntemler: Nisan 2015-Kasım 2017 tarihleri arasında Le Fort I osteotomisi yapılan ve operasyon öncesi ile prosedürden 3 ile 12 ay sonra KIBT taramaları mevcut olan 32 hasta çalışmaya dahil edildi. Planlanan cerrahi girişim tipi her hastanın spesifik deformitesine bağlıydı. Ameliyat öncesi ve sonrası sağ ve sol maksiller sinüs ventilasyon hacimlerinin volumetrik analizler ile 3 boyutlu bir yazılım kullanılarak ölçümleri yapıldı. Ayrıca maksillofasiyal deformite tipi ve septa varlığı her hasta için ayrı ayrı kaydedildi. Her bir değișken için tanımlayıcı istatistikler hesaplandı ve pre/postoperatif değerleri karşılaştırmak için bağımlı örneklemler t-testi kullanıldı.

Bulgular: 32 olgunun (17 kadın, 15 erkek) verileri (yaş ortalaması 26.40 \pm 7.54 ; ortalama takip süresi 5.25 ay) incelendi. Hastalar çeşitli maksillofasiyal deformitelere sahipti (8 hasta sınıf II, 24 hasta sınıf III). Operasyon öncesinde 27 hastada sağ veya sol maksiller sinüslerde septa formasyonuna rastlandı. Postoperatif sol maksiller sinüs ventilasyon hacminde \% 25.01; sağ maksiller sinüs ventilasyon hacminde \% 18.01'lik bir azalma saptandı. Ameliyat sonrası hem sağ, hem de sol maksiller sinüs ventilasyon hacimlerindeki düşüş istatistiksel olarak anlamlıydı $(p<0.05)$.

Sonuç: Çalışma sonuçları Le Fort I osteotomilerinin sinüs sağlığı üzerinde önemli bir etkiye sahip olduğuna işaret etmektedir. Bu hastalarda maksiller sinüs enflamatuvar süreçlerinin postoperatif radyolojik bulguları, hasta takibinde KIBT taramalarının rutin olarak kullanılmasının yararlıı̆ını göstermektedir.

\section{ANAHTAR KELIMELER}

KIBT, ortognatik cerrahi, sinüs hacmi

Ortognatik cerrahi, oral ve maksillofasiyal cerrahide standart tedavi yöntemlerinden biridir. Le Fort I osteotomisi, 1859 'da Von Langenback tarafindan tanitımasından bu yana, her tip dentofasiyal deformitenin düzeltilmesi için temel cerrahi prosedür olmuştur. ${ }^{1}$ Ortognatik cerrahi ile ilişkili çeşitli faktörler, maksiller sinüslerde patolojik durumlara yol açabilir. Akut sinüzit, Le Fort I osteotomisinin nadiren görülen

\section{ABSTRACT}

Evaluation of orthognathic surgery's effect on maxillary sinus ventilation volume with СВСТ

Background: Aim of this study was to demonstrate the anatomical and morphological changes in maxillary sinuses by Cone-Beam Computed Tomography (CBCT) after Le Fort I osteotomy.

Methods: 32 patients, with Le Fort I osteotomy performed between April 2015-November 2017 and with CBCT scans taken 3 to 12 months after the procedure, were included in this study. Surgical intervention type was dependent on specific deformity of each patient. Preoperative/postoperative and right/left maxillary sinus ventilation volumes were measured with volumetric analyzes by using a 3D software.In addition, presence of septa and maxillofacial deformity type were recorded for each patient. Descriptive statistics were calculated for each variable and paired sample t-test was used to compare pre/postoperative values.

Results: Data of 32 patients ( 17 female; 15 male) were examined (mean age 26.40 \pm 7.54 ; mean follow-up period 5.25 months). The patients had various maxillofacial deformities (8 patients had class II; 24 patients had class III malocclusion). In 27 patients, septa formation was observed in the right and left maxillary sinuses before the operation. Ratio of postoperative decrease in left maxillary sinus ventilation volume was \% 25.01 and in right maxillary sinus ventilation volume was $\% 18.01$. The decrease in both right and left maxillary sinus ventilation volumes after surgery was statistically significant $(p<0.05)$.

Conclusion: Results of the study indicate that Le Fort I osteotomies may have a significant effect on sinus health. The postoperative radiological findings of the maxillary sinus inflammatory processes in these patients point out usefulness of CBCT scans in patient follow-up.

\section{KEYWORDS}

СВСТ, orthognathic surgery, sinus volume

komplikasyonlarından biridir. ${ }^{2}$ Le Fort I osteotomisinin pre/postoperatif olarak maksiller sinüslerin anatomisi ve fonksiyonu üzerindeki etkisi rutinde çoğu zaman değerlendirilen bir durum değildir. Nadiren de olsa, maksiller sinüslerin anatomisi ve fizyolojisinin cerrahiye bağlı modifikasyonları ile karşılaşılmakta ve buna bağı oluşabilecek komplikasyonlar osteotominin gecikmiş konsolidasyonu, sinüsün enfeksiyonları ve postoperatif

\footnotetext{
* Bu araştırma Çukurova Üniversitesi Bilimsel Araştırma Projeleri Koordinatörlüğü tarafindan TSA-2019-11525 proje numarasıyla desteklenmiştir Bu çalışma, CED-IADR/NOF Oral Health Research Congress (19-21 Eylül 2019, Madrid, İspanya) adlı uluslararası kongrede sözlü bildiri olarak sunulmuştur..
}

${ }^{\alpha}$ Çukurova Üniversitesi Diş Hekimliği Fakültesi Ağız, Diş ve Çene Radyolojisi Anabilim Dalı, Adana 
kanama olarak karşımıza çıkmaktadır. ${ }^{3,4}$ Çeşitli maksillofasiyal travmalar sonrasında, sinüzit varlığında, oral ve maksillofasiyal cerrahi ve dental implant uygulamalarında maksiller sinüslerin değerlendirilmesi önemlidir. ${ }^{5}$ Maksiller sinüsün kompleks anatomik yapısına bakıldığında, manyetik rezonans görüntüleme (MRG) ve Bilgisayarlı Tomografi (BT) gibi tanı yöntemleri, sinüslerin gerçek anatomisini değerlendirmek için altın standart olarak kullanılmaktadır. ${ }^{6}$ Bununla birlikte kullanımları; yüksek maliyet, erişilebilirliğinin kısıtlı olması ve BT için yüksek doz radyasyon kullanılması nedeni ile sınırlıdır. Konik ışınlı bilgisayarlı tomografi (KIBT) ile bu dezavantajların üstesinden gelinmiştir. 1998 yılında diş hekimliğinde tanıtılmasından itibaren rutin uygulamalarda bu tekniği kullanan klinisyenlerin sayısı sürekli artmıştır. ${ }^{7}$ KIBT, yüksek çözünürlük ve düşük doz radyasyon maruziyeti ile hızlı hacimsel görüntü elde edilmesini sağladığı için dişler ve etrafındaki kompleks anatomik yapılar hakkında kesin bilgiler sunabilmektedir. ${ }^{8}$ KIBT'nin en önemli avantajları, yüksek kontrastlı yapıların yüksek görüntü kalitesi ile görüntülenebilmesi, geometrik distorsiyon olmaması ve anatomik yapıların süperpozisyonlarının engellenmesidir. ${ }^{9} \mathrm{Bu}$ çalışmanın amacı, Le Fort I osteotomisi sonrası maksiller sinüslerdeki ventilasyon hacim değişikliklerinin KIBT ile değerlendirilmesidir.

\section{GEREÇ VE YÖNTEM}

Le Fort I osteotomisinden sonra maksiller sinüslerdeki ventilasyon hacim değişikliklerini değerlendirmek amacıyla retrospektif ve gözlemsel bir araştırma olarak planlanan çalışmamız için Çukurova Üniversitesi Tıp Fakültesi Girişimsel Olmayan Klinik Araştırmalar Etik Kurulu'ndan gerekli izin alındı (Protokol no:2018/8334). Nisan 2015-Kasım 2017 tarihleri arasında Çukurova Üniversitesi Diş Hekimliği Fakültesi'ne başvuran, çeşitli maksillofasiyal deformitelere sahip; yaş ortalaması $26.40 \pm 7.54$ olan, 17 'si kadın, 15 'i erkek, 32 hastanın ameliyattan 1 hafta önce alınmış preoperatif KIBT (Planmeca ProMax ${ }^{\circledR}$ 3D Mid, Helsinki, Finland; FOV alanı: 450x450x436 mm; ekspoz parametreleri: $90 \mathrm{kV}, 10 \mathrm{~mA}, 27 \mathrm{sn}$ tarama süresi) ve ameliyattan 3 ila 12 ay sonra (ortalama takip süresi 5.25 ay) alınmış postoperatif KIBT taramaları kullanıldı. Planlanan cerrahi girişim tipi (Le Fort I osteotomi) her hastanın spesifik deformitesine bağlıydı. Tüm hastalara titanyum miniplaklar ve teller ile fiksasyon uygulanmıştı. Volumetrik analizler, veri setlerini kolaylaştıran güçlü bir araç olan Dolphin 3D yazılımı (version 11.95; Dolphin Imaging \& Management Solutions, Chatsworth, California) kullanılarak işlendi. Yazılım programında hacimleri ölçmek için aksiyal, koronal ve sagittal planlarda sinüs boşluğunu çevreleyen sınır çizgileri işaretlendi. İşaretleme noktaları daha sonra sinüs boşlukları içerisine bütün sinüs dahil edilinceye kadar yerleştirildi. Sinüs ventilasyon hacmi "Güncelleme Hacmi" sekmesi ile oluşturuldu. Ameliyat öncesi ve sonrası maksiller sinüs ventilasyon hacimleri belirlendi (Şekil 1, Şekil 2). Yazılım, sinüs boşlukları içindeki hava hacmi ile hipertrofik inflamatuvar mukozal kalınlaşma hariç rezidüel alandaki hacmin hesaplanmasına olanak sağlamıştır. Maksiller sinüs ventilasyon hacmi ölçümünde "eşik değeri belirleme - Thresholding" için dinamik threshold değeri "55" HU (Hounsfield Unit) olarak seçilerek bir maske oluşturuldu. İstatistiksel analizlerde SPSS 20.0 istatistik yazılımı (SPSS Inc., Chicago, IL, USA) kullanıldı. Hastaların ameliyat öncesi ve sonrası maksiller sinüslerinin ventilasyon hacimleri arasında anlamlı bir fark olup olmadığı bağımlı örneklem t-testi ile değerlendirildi. Anlamlılık düzeyi $p<0.05$ olarak belirlendi.

\section{BULGULAR}

Çalışma grubunu oluşturan, yaş ortalaması $26.40 \pm$ 7.54 olan, 17'si kadın, 15'i erkek toplam 32 hasta değerlendirilmeye alındı. Hastaların 8'i sınıf II, 24'ü sınıf III maksillofasiyal deformiteye sahipti. Operasyon öncesinde 27 hastada sağ veya sol maksiller sinüste septa formasyonuna rastlandı. Sağ, sol ve sağ/sol total maksiller sinüslerin preoperatif ve postoperatif ventilasyon hacimleri normal bir dağılım göstermiştir. Pre-postoperatif ventilasyon hacimlerindeki farklılıkları analiz etmek için bağımlı örneklemler t testi kullanıldı. Preoperatif sol maksiller sinüs ventilasyon hacminin ortalaması $16996.28 \mathrm{~mm}^{3}$, sağ maksiller sinüs ventilasyon hacminin ortalaması $16033.59 \mathrm{~mm}^{3}$; postoperatif sol maksiller sinüs ventilasyon hacminin ortalaması $12745.28 \mathrm{~mm}^{3}$, sağ maksiller sinüs ventilasyon hacminin ortalaması $13146.06 \mathrm{~mm}^{3}$ 'tü. Postoperatif sol maksiller sinüs ventilasyon hacminde \% 25.01'lik, postoperatif sağ maksiller sinüs ventilasyon hacminde \% 18,01'lik bir azalma saptandı. Sağ ve sol 64 maksiller sinüsün 3 tanesinde (\% 4.68) ameliyattan sonra sinüs ventilasyon hacminde artış gözlenmiştir. Ameliyat sonrası hem sağ, hem sol, hem de sağ/sol total maksiller sinüs ventilasyon hacimlerindeki düşüş istatistiksel olarak anlamlıydı $(p=.000)$ (Tablo 1, Şekil 3) 

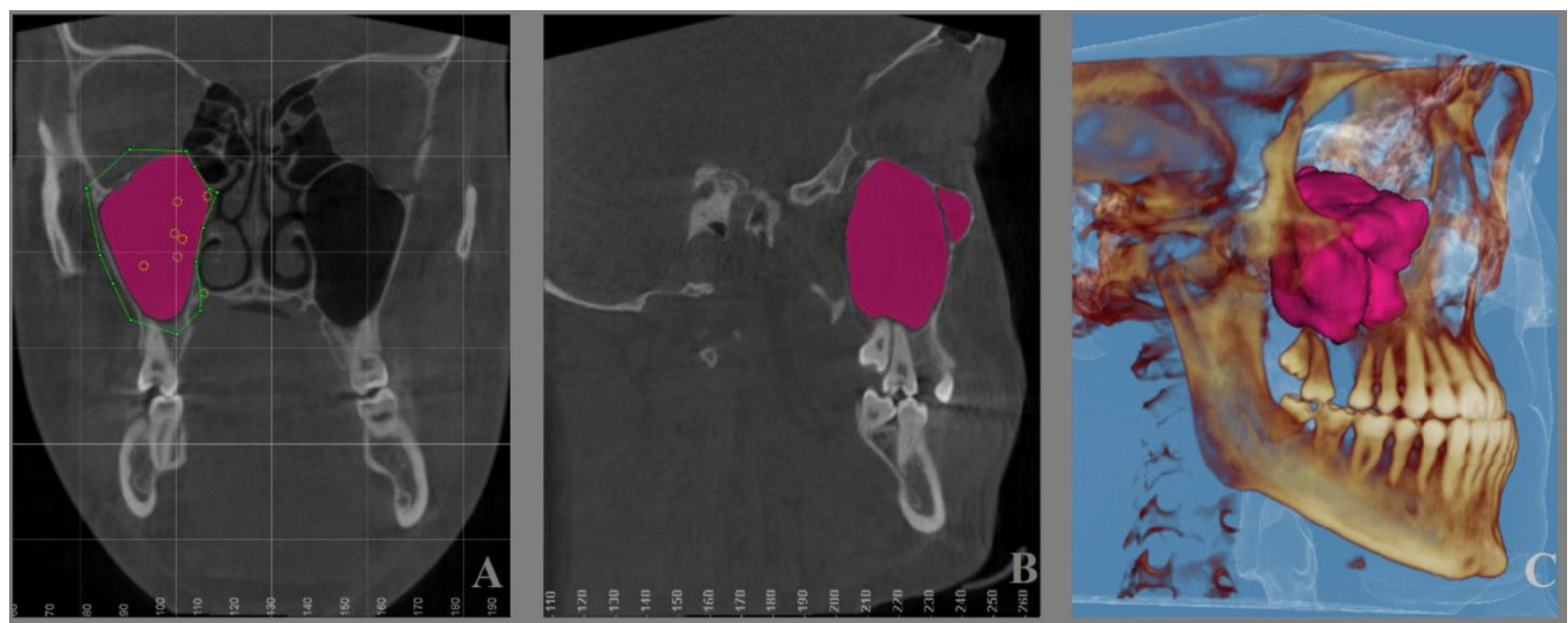

Şekil 1.

Ameliyat öncesi sağ maksiller sinüs ventilasyon hacim ölçümü A) Koronal kesit görünümü B) Sagital kesit görünümü C) Sağ maksiller sinüs ventilasyon hacminin ölçüm sonrası oluşturulan 3 boyutlu görünümü
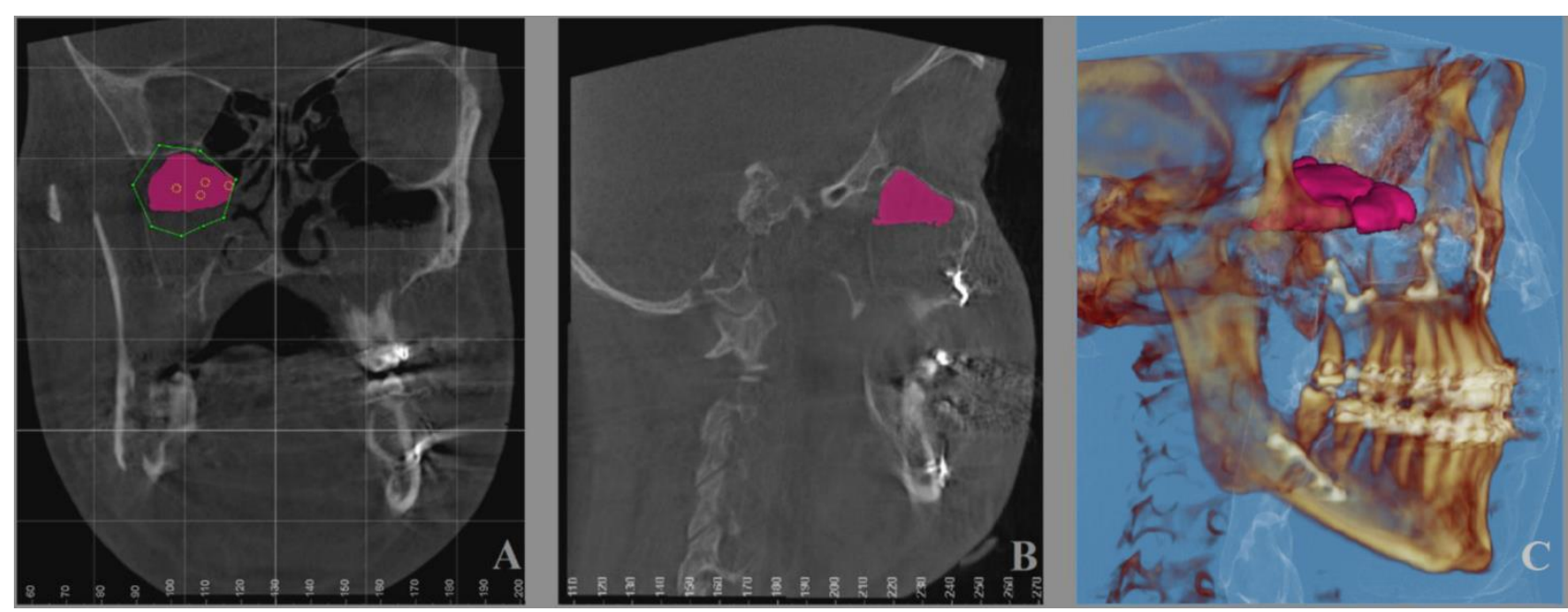

Şekil 2.

Aynı hastanın ameliyat sonrası sağ maksiller sinüs ventilasyon hacim ölçümü. A) Koronal kesit görünümü B) Sagital kesit görünümü C) Sağ maksiller sinüs ventilasyon hacminin ölçüm sonrası oluşturulan 3 boyutlu görünümü
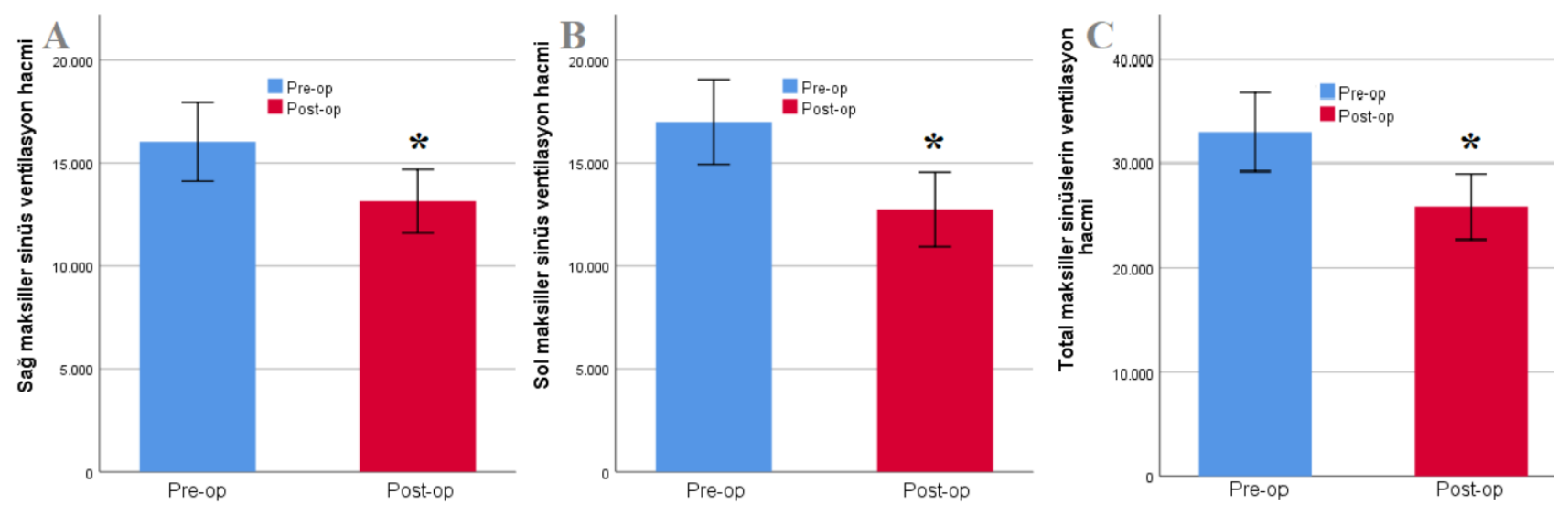

Şekil 3.

Ameliyat öncesi (pre-op) ve ameliyat sonrası (post-op) maksiller sinüs ventilasyon hacimleri A) Sağ maksiller sinüs ventilasyon hacmi B) Sol maksiller sinüs ventilasyon hacmi C) Total maksiller sinüslerin ventilasyon hacimleri. * ameliyat öncesi ve ameliyat sonrası arasındaki anlamlı farklılıkları gösterir $(p=0.000)$ 
Tablo 1.

Ameliyat öncesi (pre-op) ve ameliyat sonrası (post-op) maksiller sinüs ventilasyon hacimleri

\begin{tabular}{|lccc|c|} 
& \multicolumn{2}{c}{ Ventilasyon Hacmi $\left(\mathrm{mm}^{3}\right)$} & & \\
\cline { 2 - 4 } & \multicolumn{1}{c}{ Pre-op } & Post-op & Sayı (N) & p \\
\hline Sağ Maksiller Sinüs & $16033.59 \pm 5309.30$ & $13146.06 \pm 4286.44$ & 32 & $.000^{*}$ \\
\hline Sol Maksiller Sinüs & $16996.28 \pm 5716.25$ & $12745.28 \pm 5015.26$ & 32 & $.000^{*}$ \\
\hline Total Maksiller Sinüsler & $33029.88 \pm 10460.17$ & $25891.34 \pm 8731.96$ & 64 & $.000^{*}$ \\
\hline
\end{tabular}

Değerler ortalama \pm standart sapma olarak verildi. * gruplar arasındaki anlamlı farklııkları gösterir $(p=0.000)$.

\section{TARTIŞMA}

Sinüs tabanının yükseltilmesini gerektiren cerrahi işlemlerden önce maksiller sinüslerin anatomik yapısının ve varyasyonlarının radyografik olarak değerlendirilmesi zorunludur. Radyolojik değerlendirme ile sinüs tabanı yüksekliği, implant planlaması, sinüste septa, yabancı cisim veya enfeksiyon varlığı gibi durumlar tespit edilebilir. KIBT'nin, maksiller sinüs analizi için değerli bir tanı aracı olduğu ve doğruluğu kanıtlanmıştır. ${ }^{10-13}$ KIBT görüntüleri kullanılarak, anatomik yapıların lineer ölçümlerinin yanı sıra hacimleri de ölçülebilir. ${ }^{1}$ Ortognatik cerrahi, oral ve maksillofasiyal cerrahinin ana uzmanlık alanlarından biridir ve günümüzde dünya çapında çok sayıda prosedür rutin olarak yapılmaktadır. Her ne kadar uzun süreli klinik sonuçlar ve komplikasyonlar değerlendirilmiş olsa da ortognatik cerrahi prosedürlerinde rol oynayan nazal kavite ve paranazal sinüslerin anatomik ve semptomatik değişiklikleri ile ilgili az sayıda veri mevcuttur. ${ }^{14,15} \mathrm{Bu}$, kısmen radyolojik değerlendirmelerin yetersizliği ile açıklanabilir. Çoğu ortognatik cerrahi prosedürü, rinosinüzit gibi patolojileri saptama olasılığını sınırlayan 2 boyutlu görüntüleme yöntemleri kullanılarak planlanmaktadır. Pereira-Filho ve ark. ${ }^{16}$ Le Fort I osteotomisi uygulanan 21 erişkin hastada, kısa bir anket, radyografiler (Waters grafileri) ve ameliyat öncesi nazal endoskopi ve postoperatif 6 ila 8 ay sonra maksiller sinüzit insidansını değerlendirmiştir. Postoperatif komplikasyon olarak \% 4'lük bir maksiller sinüzit insidansı gösteren sonuçlar, ortognatik cerrahinin doğrudan kronik veya subakut sinüzitin başlangıcıyla bağlantılı olmadığını düşündürmüştür. Valstar ve ark. ${ }^{17}$ nazal inspiratuvar değişiklikleri tespit etmek için nazal endoskopi uyguladıkları 20 hastada yaptıkları çalışmalarında BT ile paranazal sinüslerin anatomik ve radyolojik değişikliklerini değerlendirmiştir. Değerlendirmeler ameliyat öncesi ve ameliyattan 2 ay sonra yapılmıştır. Sinonazal şikayetleri, maksiller sinüs ve nazal ventilasyonu değerlendirmek için hastalara anket uyguladıkları bu araştırmada Le Fort I osteotomisinin var olan şikayetleri etkilemediği ve hastaların nazal ventilasyonunun olumsuz etkilenmediği sonucuna varmışlardır. Nocini ve ark. ${ }^{18}$ yaptıkları çalışmada ameliyat öncesi ve ameliyat sonrası KIBT taraması olan 64 hastaya sinonazal sonuç testi20 (SNOT-20) uygulamıştır. Hastaların 12'sinde (\% 18.75) ameliyattan 1 yıl sonra radyolojik olarak sinüzitin göstergelerinin geliştiği gösterilmiştir. Genel olarak, hastaların \% 30'unda paranazal sinüsleri etkileyen postoperatif inflamatuar süreçlerin de kanıtı görülmüştür. Preoperatif sinüzitli hastalar için Le Fort I osteotomisinde mutlak kontrendikasyonun bulunmadığını tespit ettikleri çalışmalarında ortognatik cerrahi geçiren hastalarda sıklıkla asemptomatik olan ve kolaylıkla teşhis edilemeyen, postoperatif inflamatuar süreçlerin ve iyatrojenik değişikliklerin yüksek insidansının altını çizmişlerdir. Rinosinüzitin patolojik etiyolojisinde maksiller sinüs volüm azalmasının sorumlu olup olmadığı açık değildir. insidansının altını çizmişlerdir. Rinosinüzitin patolojik etyolojisinde maksiller sinüs hacim azalmasının sorumlu olup olmadığı açık değildir. Semptomlar mevcutsa, cerrahi işlem öncesi rinosinüzitin tedavisi yapılmalıdır. Ortognatik cerrahi sonrası mevcut rinosinüzitin iyileştiği hastalarda muhtemelen cerrahi prosedürün ve iltihaplı dokunun sinüs alt bölümünden çıkarımasının maksiller sinüs içindeki hava akımı üzerine olumlu bir etkisi olmaktadır. Bizim elde ettiğimiz sonuçlar da Le Fort I osteotomisine giren hastalarda yüksek oranda komplikasyon oluştuğunu göstermiştir. Bulgularımız Nocini ve ark.nın ${ }^{18}$ çalışmalarına paralel olarak, maksiller sinüs ventilasyon hacminde kayda değer bir azalma olduğunu, ortognatik cerrahi hastalarının klinik takiplerinin sadece oklüzal düzlemde ve maksilladaki postoperatif stabilite ile sınırlı kalmaması gerektiğini; aynı zamanda sinüsler ile çevre sert ve yumuşak dokuların dengesini etkileyebilecek faktörler üzerinde de odaklanılması gerektiğini göstermiştir.

\section{SONUÇ}

KIBT, Le Fort I osteotomisi geçiren hastalarda gelişebilecek; mukozal kalınlaşma, ventilasyon hacminin azalması, sinüzit gibi komplikasyonların tespit edilmesinde uzun vadeli ve güvenilir sonuçlar veren bir görüntüleme yöntemidir. Çeşitli deformitelere sahip hastaların takip sürecinde, sadece dengeli bir okluzyonunun sağlanması ile estetik ve fonksiyonel olarak normal sınıra getirilmesi açısından değil, radyolojik olarak da değerlendirilmesi gerekmektedir. Operasyon sonrası gelişebilecek komplikasyonları açıklığa kavuşturabilmek için daha çok hasta üzerinde, daha uzun vadeli çalışmalar yapılması yararlı olacaktır. 


\section{KAYNAKLAR}

1. De Mol Van Otterloo JJ, Tuinzing DB, Greebe RB, Van Der Kwast WA. Intra and early postoperative complications of the Le Fort I osteotomy: a retrospective study on 410 cases. J Craniomaxillofac Surg 1991; 19: 217-22.

2. Steel BJ, Cope MR. Unusual and rare complications of orthognathic surgery: A literature review. J Oral Maxillofac Surg 2012; 70: 1678-91.

3. Perko M. Maxillary sinus and surgical movement of maxilla. Int J Oral Surg 1972; 1(4): 177-84.

4. Bell CS, Thrash WJ, Zysset MK. Incidence of maxillary sinusitis following Le Fort I maxillary osteotomy. J Oral Maxillofac Surg 1986; 44(2): 100-3.

5. Luz J, Greutmann D, Wiedemeier D, Rostetter C, Rücker M, Stadlinger B. 3D-evaluation of the maxillary sinus in cone-beam computed tomography. Int $\mathrm{J}$ Implant Dent 2018; 4:17.

6. Saccucci M, Cipriani F, Carderi S, Di Carlo G, D'Attilio $M$, Rodolfino $D$, et al. Gender assessment through three-dimensional analysis of maxillary sinuses by means of Cone Beam Computed Tomography. Eur Rev Med Pharmacol Sci 2015; 19: 185-93.

7. Mozzo P, Procacci C, Tacconi A, Martini PT, Andreis IAB. A new volumetric CT machine for dental imaging based on the cone-beam technique: preliminary results. Eur Radiol 1998; 8(9): 1558-64.

8. Ayeesha U, Bharati AP. Sexual Dimorphism of Maxillary Sinus: A Morphometric Analysis using Cone Beam Computed Tomography. J Clin Diagn Res 2017; 11(3): ZC67-ZC70.

9. Price JB, Thaw KL, Tyndall DA, Ludlow JB, Padilla RJ. Incidental findings from cone beam computed tomography of the maxillofacial region: a descriptive retrospective study. Clin Oral Implants Res.2012; 23(11): 1261-8.

10. Chau AC, Fung K. Comparison of radiation dose for implant imaging using conventional spiral tomography, computed tomography, and cone-beam computed tomography. Oral Surg Oral Med Oral Pathol Oral Radiol Endod 2009; 107(4): 559-65.

11.Loubele $M$, Jacobs R, Maes F, Denis K, White $S$, Coudyzer W. et al. Image quality vs radiation dose of four cone beam computed tomography scanners. Dentomaxillofac Radiol 2008; 37(6): 309-18.

12.Pinsky HM, Dyda S, Pinsky RW, Misch KA, Sarment DP. Accuracy of three-dimensional measurements using cone-beam CT. Dentomaxillofac Radiol 2006; 35(6): 410-6.

13.Tolstunov L, Thai D, Arellano L. Implant-guided volumetric analysis of edentulous maxillary bone with cone-beam computerized tomography scan. Maxillary sinus pneumatization classification. J Oral Implantol 2012; 38(4): 377-90.
14.Panula K, Finne K, Oikarinen K. Incidence of complications and problems related to orthognathic surgery: A review of 655 patients. J Oral Maxillofac Surg 2001; 59(10): 1128-36.

15. Bacci C, Berengo M, Favero L, Zanon E. Safety of dental implant surgery in patients undergoing anticoagulation therapy: A prospective casecontrol study. Clin Oral Implants Res 2011; 22(2): 151-6.

16.Pereira-Filho VA, Gabrielli MF, Gabrielli MA, Pinto FA, Rodrigues-Junior AL, Klüppel LE et al. Incidence of maxillary sinusitis following Le Fort I osteotomy: Clinical, radiographic, and endoscopic study. J Oral Maxillofac Surg 2011; 69: 346-51.

17. Valstar MH, Baas EM, Te Rijdt JP, De Bondt BJ, Laurens $\mathrm{E}$, De Lange J. Maxillary sinus recovery and nasal ventilation after Le Fort I osteotomy: A prospective clinical, endoscopic, functional and radiographic evaluation. Int $\mathrm{J}$ Oral Maxillofac Surg 2013; 42(11): 1431-6.

18. Nocini PF, D'Agostino A, Trevisiol L, Favero V, Pessina M, Procacci P. Is Le Fort I Osteotomy Associated With Maxillary Sinusitis? J Oral Maxillofac Surg 2016; 74(2): 400.e1- 400.e12.

Yazışma Adresi:

Hazal DUYAN

Çukurova Üniversitesi

Ağız, Diş ve Çene Radyolojisi AD

Adana, Türkiye

Tel : : +9032233873 30

Faks : +90322 3387331

E Posta: hazalduyan@hotmail.com 